\title{
Índices de vegetação de base espectral para discriminar doses de nitrogênio em capim-tanzânia
}

\section{Selma Alves Abrahão ${ }^{1}$, Francisco de Assis de Carvalho Pinto ${ }^{2}$, Daniel Marçal de Queiroz ${ }^{3}$, Nerilson Terra Santos ${ }^{3}$, José Marinaldo Gleriani ${ }^{4}$, Enrique Anastácio Alves ${ }^{2}$}

\footnotetext{
1 Doutorando do Departamento de Engenharia Agrícola da UFV. CEP: 36571-000, Viçosa, MG

2 Departamento de Engenharia Agrícola da UFV. CEP: 36571-000, Viçosa, MG.

${ }^{3}$ Departamento de Informática da UFV . CEP: 36571-000, Viçosa, MG.

${ }^{4}$ Departamento de Engenharia Florestal da UFV. CEP: 36571-000, Viçosa, MG.
}

RESUMO - Este trabalho foi realizado para determinar, entre seis índices de vegetação baseados em dados de refletância espectral, aquele que melhor discrimina doses de nitrogênio e que possui maior correlação com leituras de clorofila e massa seca do capim-tanzânia (Panicum maximum Jacq.). Os índices testados foram o NDVI (índice de vegetação por diferença normalizada, calculado utilizando a banda do vermelho e a banda do infravermelho próximo), VARI (índice resistente à atmosfera na região do visível, calculado utilizando a banda de transição do vermelho ao infravermelho e a banda do verde) e WDRVI (índice de vegetação de amplo alcance, calculado utilizando três coeficientes de ponderação, 0,05; 0,1 e 0,2). Foram avaliadas quatro doses de nitrogênio $(0,80,160$ e $320 \mathrm{~kg} / \mathrm{ha})$ em delineamento de blocos ao acaso com subamostras, com três repetições e três subamostras por bloco. Os índices VARI utilizando a banda de transição do vermelho ao infravermelho e o WDRVI utilizando os coeficientes 0,05 e 0,1 foram os melhores para discriminar as doses de nitrogênio aplicadas em todos os períodos de avaliação estudados. O índice que apresentou maior correlação com as leituras de clorofila e massa seca foi o VARI com banda de transição do vermelho ao infravermelho.

Palavras-chave: leituras de clorofila, massa seca, Panicum maximum Jacq., refletância espectral

\section{Vegetation spectral indices to discriminate nitrogen rates in tanzania grass}

ABSTRACT - The objective of this study was to determine, among five vegetation indices, calculated based on spectral reflectance data, the one that best discriminated nitrogen rates, and presented highest correlation with chlorophyll readings and tanzania grass (Panicum maximum Jacq.) dry matter. The tested vegetation indices were NDVI (normalized difference vegetation index), VARI (visible atmospherically resistant index using red edge and green bands), WDRVI (wide dynamic range vegetation index using three weighted coefficients, $0.05,0.1$ and 0.2 ). Four nitrogen levels (0, 80, 160 and $320 \mathrm{~kg} / \mathrm{ha}$ ) were evaluated in a randomized complete block design with three replications and three subsamplings per block. The indices VARI, using red edge band, and WDRVI, using weighted coefficients 0.05 and 0.1 , were the best indices to discriminate nitrogen rates. The index that presented the highest correlation with chlorophyll readings and dry matter was the VARI using red edge band.

Key Words: chlorophyll readings, dry mass, Panicum maximum Jacq., spectral reflectance

\section{Introdução}

O Brasil é o país com o maior rebanho bovino comercial e o segundo maior produtor de carne bovina (USDA, 2009). Entretanto, diversos autores relatam que a maior parte das áreas de pastagens no Brasil apresenta-se degradada ou em processo de degradação, com perda do potencial produtivo e da capacidade de suporte animal (Oliveira et al., 2001; Barcellos et al., 2001).

Entre as técnicas de manejo utilizadas, a adubação nitrogenada em pastagens é uma das medidas fundamentais para aumentar a produtividade das pastagens, pois o nitrogênio é um dos nutrientes limitantes no crescimento das plantas (Moreira et al., 2005). Entretanto, o elevado custo da adubação nitrogenada muitas vezes limita o uso de altas doses. Além disso, o nitrogênio aplicado ao solo está sujeito a perdas por volatilização, imobilização por microrganismos e lixiviação (Carvalho \& Saraiva, 1987).

No desenvolvimento de uma cultura, existe uma variabilidade espacial e temporal da produtividade dentro de mesma área, principalmente em virtude da disponibilidade nutricional decorrente das propriedades físicas e químicas 
do solo. Assim, determinando essa variabilidade, é possível identificar algumas causas que poderão ser corrigidas em tempo hábil, aumentando a produtividade (Diker \& Bausch, 2003).

Neste contexto, a agricultura de precisão pode ser considerada um sistema de gerenciamento sítio específico da atividade agrícola com base em informações de mapas que contenham a variabilidade espacial dos fatores de produção com o objetivo de aumentar a eficiência do processo produtivo (Queiroz et al., 2000). Uma das fontes de informação para a agricultura de precisão constitui-se em dados adquiridos por meio do sensoriamento remoto, que consiste em obter dados espectrais relacionados às características agronômicas das culturas e que definem a sua variabilidade espacial. Esses dados espectrais podem ser transformados em índices de vegetação, que têm por função correlacionar com a variável em estudo, por exemplo, o status nutricional, e reduzir esses fatores de variação, como a arquitetura do dossel e a geometria de iluminação e de visada.

Dessa forma, os objetivos neste trabalho foram determinar, entre seis índices de vegetação, o melhor para discriminar as doses de nitrogênio e estudar a correlação desses índices com leituras de clorofila e massa seca em Panicum maximum Jacq., cv. Tanzânia.

\section{Material e Métodos}

O experimento foi realizado no Setor de Forragicultura do Departamento de Zootecnia da Universidade Federal de Viçosa, MG em pastagem de Panicum maximum Jacq. cv. Tanzânia estabelecida em dezembro de 2005. O solo da área é classificado como Latossolo Vermelho-Amarelo argiloso, relevo plano. A partir dos resultados da análise química do solo e dos cortes de uniformização do capimtanzânia, foram aplicados $50 \mathrm{~kg} /$ ha de superfosfato simples (20\% de $\mathrm{P}_{2} \mathrm{O}_{5}$ ), distribuídos uniformemente em toda a área experimental (Cantarutti et al., 1999).

O delineamento experimental utilizado foi de blocos ao acaso com subamostras (Gomes, 1981). Foram avaliadas quatro doses de nitrogênio (0, 80, 160 e 320 kg/ha), na forma de ureia $(40 \%$ de $N)$, com três repetições e três subamostras por bloco. As unidades experimentais, ou parcelas, consistiram de áreas de $3 \times 3 \mathrm{~m}$, separadas entre si por corredores de $1 \mathrm{~m}$ de largura.

Durante o período de desenvolvimento do experimento, foram realizados dois cortes das plantas a $30 \mathrm{~cm}$ do solo, utilizando-seroçadeira motorizada, em 19/11/2006e 24/12/2006. Depois de cada corte, procedeu-se à reaplicação das doses de nitrogênio pré-determinadas, parceladas em duas aplicações espaçadas em sete dias para cada corte, em decorrência da presença de uma dose de nitrogênio alta (320 kg/ha).

Foram realizadas três avaliações: a primeira em 19/12/2006, ou seja, 30 dias após o primeiro corte e 20 dias após a aplicação do adubo nitrogenado. Após o segundo corte, foram realizadas a segunda e a terceira avaliação, sendo que a segunda avaliação foi realizada 15 dias após o segundo corte e 13 dias após a primeira aplicação do adubo nitrogenado. A terceira avaliação foi realizada 26 dias após o segundo corte e 11 dias após a segunda parcela de aplicação do adubo nitrogenado (Tabela 1).

Como a precipitação ocorrida durante o período experimental foi adequada, com média de 185,2 mm em novembro de 2006, 221,4 mm em dezembro de 2006 e 298,4 mm em janeiro de 2007, não foi necessário irrigar as plantas.

As medidas de refletância espectral do dossel da forrageira foram obtidas no mesmo período, entre 11 e 13 horas, reduzindo as mudanças na geometria de iluminação na refletância da cultura, de modo que, para cada avaliação, foi realizada uma única medição de refletância espectral por parcela.

As medidas de refletância espectral foram feitas utilizando um sistema "dual-fiber", com dois espectrorradiômetros, modelo SD2000, utilizados para obter dados nos comprimentos de onda entre 400 e 900 nm, com resolução espectral de $0,34 \mathrm{~nm}$. O primeiro espectrorradiômetro equipado com uma fibra óptica com campo de visão de $25^{\circ}$ foi apontado a nadir para medir a radiância do dossel da forrageira. O segundo espectrorradiômetro, equipado com uma fibra óptica e um receptor com correção de cosseno (sensor que não mostra dependência no ângulo zênite ou azimute da radiação incidente) foi apontado para o zênite para, simultaneamente ao primeiro sensor, medir a

Tabela 1 - Datas das atividades desenvolvidas durante o experimento

\begin{tabular}{lccc}
\hline Período correspondente & $1^{\text {a }}$ parcela do adubo com nitrogênio & 2a parcela do adubo com nitrogênio & Data das avaliações \\
\hline $19 / 11 / 2006$ a $19 / 12 / 2006$ & $22 / 11 / 2006$ & $29 / 11 / 2006$ & $19 / 12 / 2006$ \\
& & $8 / 1 / 2007 *$ \\
$24 / 12 / 2006$ a $20 / 1 / 2007$ & $26 / 12 / 2006$ & $8 / 1 / 2007$ & $19 / 1 / 2007$ \\
\hline
\end{tabular}

* As parcelas desta data de avaliação receberam as seguintes doses de adubo nitrogenado: 0, 40, 80 e $160 \mathrm{~kg} / \mathrm{ha}$. 
irradiância do sol. Os espectrorradiômetros foram instalados em uma estrutura, de forma que as medições foram feitas a uma altura de 3,0 m, compreendendo um campo de visada com diâmetro de aproximadamente 1,4 m. A posição da altura dos espectrorradiômetros sobre a forrageira foi mantida constante durante todas as épocas de desenvolvimento.

As medidas de radiância do dossel da forrageira e irradiância do sol foram intercaladas com as medidas de radiância de um painel padrão de refletância branco Spectralon com espectro de refletância conhecido, simultaneamente com a irradiância do sol. Essa calibração foi realizada antes da medida em cada parcela e a cada 20 minutos.

Conforme a metodologia proposta por Gitelson et al. (2003), a partir desses dados foi realizado o cálculo do Fator de refletância bidirecional (FRB) do dossel para cada comprimento de onda $(\lambda)$ de cada parcela (Equação 1$)$.

$$
\rho_{\lambda}=\frac{L_{\lambda}^{\text {forrageira }}}{E_{\lambda}^{\text {inc. }}} \times \frac{E_{\lambda}^{\text {cal. }}}{L_{\lambda}^{\text {cal. }}} \times 100 \times \rho_{\lambda}^{\text {cal. }}
$$

em que: $\rho_{\lambda}$ : fator de refletância bidirecional no comprimento de onda $\lambda$, em \%; $\rho_{\lambda}^{\text {cal. }}$ : fator de refletância do painel, adimensional; $\mathrm{L}_{\lambda}^{\text {forrageira }}$ : radiância da forrageira, em $\mathrm{W} \mathrm{m}^{-2} \mathrm{sr}^{-1}$;

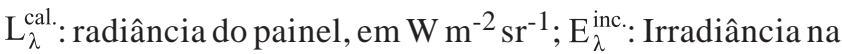
forrageira, em $\mathrm{W} \mathrm{m}^{-2} ; \mathrm{e}_{\lambda}^{\text {cal. }}$ : irradiância no painel, em W m${ }^{-2}$.

A partir do FRB, foram calculados os valores de refletância média, em intervalos de comprimento de onda correspondente às bandas azul (460 a $480 \mathrm{~nm}$ ), verde (545 a $565 \mathrm{~nm}$ ), vermelho (620 a $670 \mathrm{~nm}$ ), transição do vermelho ao infravermelho próximo (700 a $710 \mathrm{~nm}$ ) e infravermelho próximo (840 a $880 \mathrm{~nm}$ ), simulando com as bandas espectrais dos sensores MODIS (Moderate Resolution Imaging Spectrometer) e MERIS (Medium Resolution Imaging Spectrometer).

De acordo com Moreira (2005), a refletância da vegetação, de modo geral, varia com o comprimento de onda e a maior parte da radiação que incide sobre o dossel das plantas é absorvida pelos pigmentos fotossintetizantes encontrados nos cloroplastos das folhas. Os pigmentos que mais influenciam a refletância são as clorofilas "a” e "b”, que têm picos de absorção nas bandas do vermelho e do azul, respectivamente. Na banda do infravermelho próximo, a refletância é influenciada pela estrutura das folhas e do dossel das plantas.

Com os valores das bandas, foram calculados os índices de vegetação NDVI, VARI ${ }_{\text {Green }}$, VARI RedEdge $_{\text {, de }}$ acordo com as Equações 2, 3 e 4, respectivamente. O WDRVI (Equação 5) foi calculado utilizando três valores de coeficientes de ponderação $(0,05 ; 0,1$ e 0,2$)$, totalizando seis índices espectrais.

$$
\begin{aligned}
& \text { NDVI }=\frac{\rho_{\text {NIR }}-\rho_{\text {red }}}{\rho_{\text {NIR }}+\rho_{\text {red }}} \\
& \text { VARI }_{\text {Green }}=\frac{\rho_{\text {green }}-\rho_{\text {red }}}{\rho_{\text {green }}+\rho_{\text {red }}-\rho_{\text {blue }}} \\
& \text { VARI }_{\text {redEdge }}=\frac{\rho_{\text {redEdge }}-1,7 \cdot \rho_{\text {red }}+0,7 \cdot \rho_{\text {blue }}}{\rho_{\text {redEdge }}+2,3 \cdot \rho_{\text {red }}-1,3 \cdot \rho_{\text {blue }}} \\
& \text { WDRVI }=\frac{a \cdot \rho_{\text {NIR }}-\rho_{\text {red }}}{a \cdot \rho_{\text {NIR }}+\rho_{\text {red }}}
\end{aligned}
$$

em que: NDVI: índice de vegetação por diferença normalizada

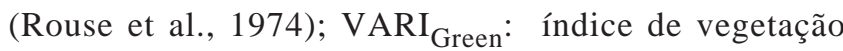
resistente à atmosfera na região do visível utilizando a banda do verde (Gitelson et al., 2002); VARI redEdge $_{\text {índice }}$ de vegetação resistente à atmosfera na região do visível utilizando a banda de transição do vermelho ao infravermelho (Gitelson et al., 2002); WDRVI: índice de vegetação dinâmico de amplo alcance (Gitelson, 2004); $\rho_{\text {blue }}$ : refletância média na banda do azul; $\rho_{\text {green }}$ : refletância média na banda do verde; $\rho_{\text {red }}$ : refletância média na banda

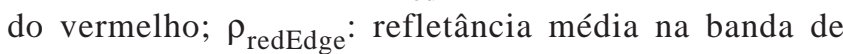
transição do vermelho ao infravermelho próximo; $\rho_{\mathrm{NIR}}$ : refletância média na banda do infravermelho próximo; e a: coeficiente de ponderação.

Estimativas do teor de clorofila em cada parcela foram obtidas de forma indireta, não-destrutiva, utilizando-se um medidor portátil de clorofila SPAD 502 nas mesmas épocas de obtenção das medidas de refletância. Em cada parcela foram obtidas aleatoriamente 30 leituras de clorofila, feitas diretamente na folha mais nova completamente expandida de diversas plantas, a partir das quais foi obtida a média dos valores, considerada o teor de clorofila da parcela.

As mesmas folhas utilizadas para estimar o teor de clorofila foram coletadas como amostras para determinar o teor de $\mathrm{N}$ total presente nas folhas, em laboratório, pelo método de Kjeldahl.

No final do experimento, foi realizada colheita da parte aérea das plantas de uma área de $1,0 \mathrm{~m}^{2}$ no centro da parcela, a uma altura de $30 \mathrm{~cm}$ do solo. Depois do corte, a forragem foi pesada no campo, com o objetivo de se determinar a massa verde. Dessa massa verde, foram retiradas amostras de $0,3 \mathrm{~kg}$. A seguir, foi realizado em laboratório o processo de secagem em estufa com circulação de ar forçada por 72 horas a $65^{\circ} \mathrm{C}$. Por fim, procedeu-se à pesagem final para estimar a produção de massa seca, em kg/ha (MS).

Com o intuito de conhecer o efeito das doses de nitrogênio sobre o teor de $\mathrm{N}$ total foliar, foi realizada uma análise de regressão com teste para falta de ajustamento do modelo de regressão adotado, para cada data de avaliação, com nível de significância de 5\%, utilizando o programa 
computacional Statistical Analysis System (SAS, 1999). Foram utilizados os seguintes modelos:

$$
\begin{aligned}
& \hat{\mathrm{Y}}=\hat{\beta}_{0}+\hat{\beta}_{1} \mathrm{~N} \\
& \hat{\mathrm{Y}}=\hat{\beta}_{0}+\hat{\beta}_{1} \mathrm{~N}+\hat{\beta}_{2} \mathrm{~N}^{2}
\end{aligned}
$$

em que: $\hat{Y}$ : teor de $\mathrm{N}$ total foliar; $\hat{\beta}_{0}$ : constante de regressão; $\hat{\beta}_{1}, \hat{\beta}_{2}$ e $\hat{\beta}_{3}$ : coeficientes da regressão; e N: dose de nitrogênio.

A escolha do modelo (Equação 6 ou 7) foi feita com base na significância do teste F para a falta de ajuste, e também pela significância de seus coeficientes, testados pelo teste t, a $5 \%$ de probabilidade. Não foram testados modelos superiores ao segundo grau, por não representarem o fenômeno biológico da cultura, pois em geral a resposta do nitrogênio foliar a doses de nitrogênio tende a ser quadrática (Primavesi et al., 2004).

As mesmas análises foram realizadas para conhecer o efeito das doses de nitrogênio aplicadas sobre os índices de vegetação utilizados.

A partir dos modelos ajustados dos índices de vegetação, foi determinado o melhor índice para discriminar as doses de nitrogênio por meio da sensibilidade do mesmo às variações de doses de nitrogênio utilizadas, calculando a relação entre o valor máximo do índice e o valor obtido sem aplicação de nitrogênio. Foi também realizada a análise de correlação entre os valores dos seis índices de vegetação e as demais características culturais estudadas (leituras de clorofila e massa de forragem seca).

\section{Resultados e Discussão}

Os teores de nitrogênio total foliar e os índices de vegetação ajustaram-se a modelos de primeiro e segundo grau, respectivamente, para todas as avaliações, o que indica que os dosséis das plantas foram influenciados pelas doses de nitrogênio (Tabelas 2, 3 e 4).
Os coeficientes de determinação para cada avaliação foram altos, o que indica que os modelos propostos são adequados para descrever o fenômeno (Tabela 5). Na primeira avaliação, 99\% da variação dos valores dos índices VARI $_{\text {RedEdge }}$ e VARI ${ }_{\text {Green }}$ do capim-tanzânia pode ser atribuída à variação da dose de nitrogênio aplicada.

Com base no modelo ajustado, aos 20 dias após a adubação, o teor de nitrogênio total foliar na parte aérea do capim-tanzânia aumentou linearmente com as doses de nitrogênio utilizadas, variando entre 1,494 e 2,431\%, respectivamente, para a não-aplicação de nitrogênio para a maior dose aplicada (320 kg/ha). Foi observado mesmo comportamento para o teor de nitrogênio total nas outras avaliações, variando entre 2,084 e 2,922\% na segunda avaliação (15 dias após o segundo corte e 13 dias após a primeira parcela de aplicação do adubo) e entre 1,846 e 2,598\% na terceira avaliação (26 dias após o segundo corte e 11 dias após a segunda parcela de aplicação do adubo). Silva Júnior (2006) também encontrou resposta linear positiva, aos 21 dias após a adubação para o teor de nitrogênio total foliar até a maior dose de nitrogênio aplicada em capim-braquiária. O teor de nitrogênio total variou de 1,619 a 2,839\% nos limites das doses de nitrogênio estudadas (0 a $200 \mathrm{~kg} / \mathrm{ha}$ ) por esse autor.

Os índices de vegetação em geral apresentaram ligeiro decréscimo com a aplicação de doses superiores a $220 \mathrm{~kg} / \mathrm{ha}$, para a primeira e terceira avaliações, e acima de $100 \mathrm{~kg} / \mathrm{ha}$, para segunda avaliação, o que pode estar relacionado a esse possível desequilíbrio nutricional da planta com altas doses de nitrogênio (Dougherty \& Rhykerd, 1985). Resultados semelhantes foram encontrados por Cunha (2004), que observaram que dosagens acima de $1.500 \mathrm{~kg} \mathrm{~N} / \mathrm{ha}$.ano parceladas em sete aplicações tenderam a reduzir os valores do NDVI do capim-tanzânia, em virtude de uma possível influência negativa dos fatores relacionados ao excesso de nitrogênio.

Tabela 2 - Resultados da análise de regressão dos índices de vegetação do capim-tanzânia em cada dose de nitrogênio 30 dias após o primeiro corte e 20 dias após a aplicação do adubo nitrogenado

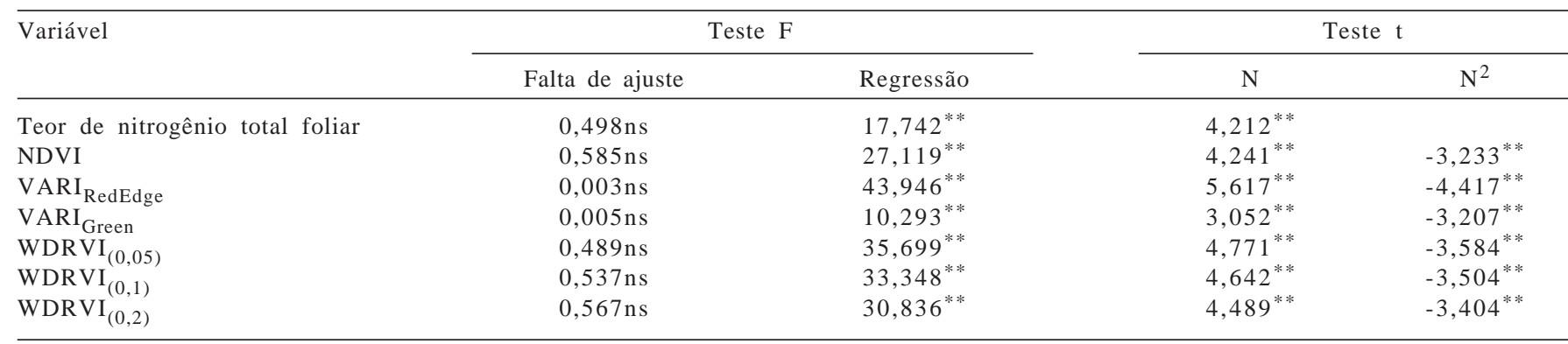

* e ** teste ao nível de 1 e 5\% de probabilidade, respectivamente; NDVI: índice de vegetação por diferença normalizada; VARI na região do visível utilizando a banda de transição do vermelho ao infravermelho próximo; VARI ${ }_{\text {Green }}$ índice de vegetação resistente à atmosfera na região do visível utilizando a banda do verde; WDRVI: índice de vegetação de amplo alcance dinâmico, calculado utilizando três valores de coeficientes de ponderação (0,05; 0,1 e 0,2). 
Tabela 3 - Resultados da análise de regressão dos índices de vegetação do capim-tanzânia em cada dose de nitrogênio 15 dias após o segundo corte e 13 dias após a primeira parcela de adubação nitrogenada

\begin{tabular}{|c|c|c|c|c|}
\hline \multirow[t]{2}{*}{ Variável } & \multicolumn{2}{|c|}{ Teste F } & \multicolumn{2}{|c|}{ Teste $\mathrm{t}$} \\
\hline & Falta de ajuste & Regressão & $\mathrm{N}$ & $\mathrm{N}^{2}$ \\
\hline Teor de nitrogênio total foliar & $0,881 \mathrm{~ns}$ & $13,702^{* *}$ & $3,702^{* *}$ & \\
\hline VARI $_{\text {RedEdøe }}$ & $0,250 \mathrm{~ns}$ & $22,199^{* *}$ & $4,138^{* *}$ & $-3,349^{* *}$ \\
\hline VARI $_{\text {Green }}$ & $0,050 \mathrm{~ns}$ & $5,738^{*}$ & $2,373^{*}$ & $-2,371^{*}$ \\
\hline $\begin{array}{l}\text { WDRVI }_{(0,05)} \\
\text { Gren }\end{array}$ & $0,227 \mathrm{~ns}$ & $14,928^{* *}$ & $3,474^{* *}$ & $-2,867^{* *}$ \\
\hline
\end{tabular}

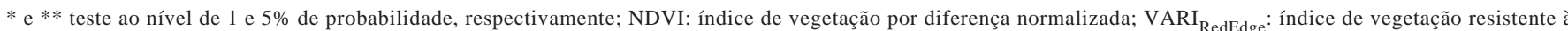
atmosfera na região do visível utilizando a banda de transição do vermelho ao infravermelho próximo; VARI ${ }_{\text {Green }}$ : índice de vegetação resistente à atmosfera na região do visível utilizando a banda do verde; WDRVI: índice de vegetação de amplo alcance dinâmico, calculado utilizando três valores de coeficientes de ponderação ( 0,05 ; 0,1 e 0,2$)$.

Tabela 4 - Resultados da análise de regressão dos índices de vegetação do capim-tanzânia em cada dose de nitrogênio 26 dias após o segundo corte e 11 dias após a segunda parcela do adubo nitrogenado

\begin{tabular}{|c|c|c|c|c|}
\hline \multirow[t]{2}{*}{ Variável } & \multicolumn{2}{|c|}{ Teste $\mathrm{F}$} & \multicolumn{2}{|c|}{ Teste $\mathrm{t}$} \\
\hline & Falta de ajuste & Regressão & $\mathrm{N}$ & $\mathrm{N}^{2}$ \\
\hline Teor de nitrogênio total foliar & $2,972 \mathrm{~ns}$ & $15,808^{* *}$ & $3,976^{* *}$ & \\
\hline VARI $_{\text {RedEdge }}$ & $1,151 \mathrm{~ns}$ & $51,711^{* *}$ & $5,759^{* *}$ & $-4,335^{* *}$ \\
\hline VARI $_{G \text { reen }}$ & 0,373 ns & $6,901^{*}$ & $2,626^{*}$ & $-2,501^{*}$ \\
\hline WDRVI $_{(005)}$ & $0,379 \mathrm{~ns}$ & $33,451^{* *}$ & $4,934^{* *}$ & $-3,900^{* *}$ \\
\hline
\end{tabular}

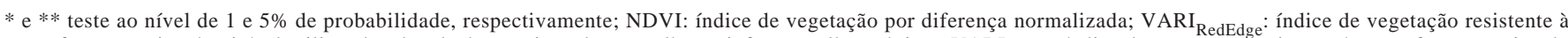
atmosfera na região do visível utilizando a banda de transição do vermelho ao infravermelho próximo; VARI visível utilizando a banda do verde; WDRVI: índice de vegetação de amplo alcance dinâmico, calculado utilizando três valores de coeficientes de ponderação (0,05; 0,1 e 0,2$)$.

O comportamento quadrático dos índices em detrimento do teor de nitrogênio total pode ser creditado ao fato de os índices serem correlacionados ao teor de clorofila presente nas folhas das plantas, o que os tornam indiretamente relacionado ao teor de nitrogênio. Segundo Bullock \& Anderson (1998), com o aumento da disponibilidade de nitrogênio para a planta, mais clorofila é produzida nas folhas, melhorando a percepção da cor verde da folha. Esse aumento da clorofila, porém, atinge um patamar designado como ponto de maturidade fotossintética, a partir do qual se mantém invariável, mesmo com o aumento da concentração de nitrogênio no tecido, o que explica o comportamento quadrático dos índices espectrais.

Trinta dias após o primeiro corte e 20 dias após a segunda parcela do adubo com nitrogênio (primeira avaliação), o WDRVI $(0,05)$ foi o melhor índice de vegetação para discriminar doses de nitrogênio, pois apresentou maior fator de multiplicação $(4,1098)$ e também maior sensibilidade ao intervalo das doses de nitrogênio utilizadas, de 0 a 229,7 kg/ha (Tabela 6). Quinze dias após o segundo corte e 13 dias após a primeira parcela da adubação nitrogenada (segunda avaliação), o WDRVI $(0,05)$ foi o melhor índice de vegetação para discriminar doses de nitrogênio $(1,7953)$,

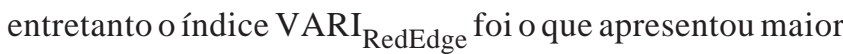
sensibilidade ao intervalo das doses de nitrogênio utilizadas, de 0 a 106,6 kg/ha. Aos 26 dias após o segundo corte e 13 dias após a segunda parcela do adubo com nitrogênio (terceira avaliação), o WDRVI $(0,1)$ também apresentou maior fator de multiplicação $(2,4398)$, entretanto oíndice VARI RedEdge $_{\text {foi }}$ o que apresentou maior sensibilidade ao intervalo das doses de nitrogênio utilizadas (0 a 229,2 kg/ha). Desse modo, o índice VARI ${\text { RedEdge, } \text { WDRVI }_{(0,05)} \text { e WDRVI }}_{(0,1)}$ indicam tendência geral de um mesmo índice para discriminar as doses de nitrogênio aplicadas nas avaliações.

Para se conhecer a relação entre os índices de vegetação que tiveram seus modelos ajustados e as leituras de clorofila do capim-tanzânia, foi realizada uma análise de correlação simples (Tabela 7). De maneira geral, predominaram valores de coeficientes altos e positivos, exceto para o índice VARI $\mathrm{Green}$, que teve correlação não significativa 
para a primeira e segunda avaliações. Na 1 ${ }^{\mathrm{a}}, 2^{\underline{a}}$ e $3^{\mathrm{a}}$ avaliações, os maiores valores dos coeficientes ocorreram para o VARI $_{\text {RedEdge, }}$ 0,82; 0,68 e 0,92, respectivamente.

O melhor coeficiente de correlação para o índice VARI $_{\text {RedEdge }}$ pode ser atribuído à região que utiliza, ou seja, a região do visível do espectro, na qual as características dos pigmentos existentes na folha dominam a resposta espectral, principalmente as clorofilas “a” "b" (Ponzoni, 2001). De acordo com Yoder \& Pettigrew-Crosby (1995), por participar diretamente na formação da molécula, existe uma forte relação entre nitrogênio e clorofila. Viña et al. (2004), ao avaliarem remotamente o desenvolvimento fenológico do milho, testaram os índices VARI RedEdge $\mathrm{e}$ VARI $_{\text {Green }}$ e concluíram que esses índices têm alta sensibilidade de resposta ao teor de clorofila presente nas folhas. Segundo os autores, esses índices podem indicar mais precocemente a fase de estresse da cultura, pois um dos sintomas do estresse é a redução do teor de clorofila.

Entretanto, neste trabalho não houve correlação

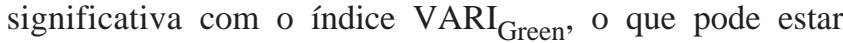
relacionado ao fato de o índice não ser normalizado por uma banda que tenha correlação com a estrutura da folha e do dossel da planta. Assim, as melhores correlações entre VARI $_{\text {RedEdge }}$ e valores SPAD podem ser explicadas pelo fato de ambos trabalharem com bandas (transição do vermelho ao infravermelho próximo e infravermelho próximo) sensíveis à variação da estrutura foliar e do dossel da planta.

O medidor de clorofila detecta a intensidade da cor verde da folha por meio da quantidade de luz de comprimentos de onda da região do vermelho e do infravermelho próximo que são transmitidas pela folha. A quantidade de luz vermelha absorvida indica a quantidade de clorofila, enquanto a quantidade de luz absorvida no infravermelho próximo serve como referência interna na compensação da espessura da folha e do conteúdo de água (Zotarelli et al., 2002).

Uma análise de correlação simples foi realizada com o objetivo de se conhecer a relação entre os índices de vegetação que tiveram seus modelos ajustados e a variável massa seca do capim-tanzânia (Tabela 8). Os maiores valores dos coeficientes foram observados para os índices VARI $_{\text {RedEdge }}$ e WDRVI $(0,05)$. Gitelson et al. (2003) testaram na cultura do milho os índices VARI $\mathrm{RedEdge}_{\text {e VARI }} \mathrm{Green}$

Tabela 5 - Resultados da análise de regressão do teor de nitrogênio total foliar e dos índices de vegetação do capim-tanzânia em cada dose de nitrogênio para todas as avaliações

\begin{tabular}{|c|c|c|c|}
\hline & & Modelo ajustado & $\mathrm{R}^{2}$ \\
\hline & \multicolumn{3}{|c|}{$1^{\mathrm{a}}$ avaliação } \\
\hline Teor de nitrogênio total & $=$ & $1,4944+2,9286 \mathrm{E}-03 \mathrm{~N}$ & 0,95 \\
\hline NDVI & $=$ & $0,8449+0,4519 \mathrm{E}-03 \mathrm{~N}-0,9989 \mathrm{E}-06 \mathrm{~N}^{2}$ & 0,96 \\
\hline VARI $_{\text {RedEdge }}$ & $=$ & $-0,3013+0,1034 \mathrm{E}-02 \mathrm{~N}-0,2356 \mathrm{E}-05 \mathrm{~N}^{2}$ & 0,99 \\
\hline VARI $_{\text {Green }}$ & $=$ & $0,6631+0,3898 \mathrm{E}-03 \mathrm{~N}-0,1187 \mathrm{E}-05 \mathrm{~N}^{2}$ & 0,99 \\
\hline $\mathrm{WDRVI}_{(0,05)}$ & $=$ & $-0,2390+0,1575 E-02 N-0,3429 E-05 N^{2}$ & 0,97 \\
\hline $\operatorname{WDRVI}_{(0,1)}$ & $=$ & $0,0979+0,1623 \mathrm{E}-02 \mathrm{~N}-0,3552 \mathrm{E}-05 \mathrm{~N}^{2}$ & 0,97 \\
\hline \multirow[t]{2}{*}{$\mathrm{WDRVI}_{(0,2)}$} & $=$ & $0,4139+0,1336 \mathrm{E}-02 \mathrm{~N}-0,2936 \mathrm{E}-05 \mathrm{~N}^{2}$ & 0,96 \\
\hline & \multicolumn{3}{|c|}{$2^{\mathrm{a}}$ avaliação } \\
\hline Teor de nitrogênio total & $=$ & $2,0804+0,52595 \mathrm{E}-02 \mathrm{~N}$ & 0,88 \\
\hline NDVI & $=$ & $0,8015+0,1132 \mathrm{E}-03 \mathrm{~N}-0,5392 \mathrm{E}-05 \mathrm{~N}^{2}$ & 0,96 \\
\hline VARI $_{\text {RedEdge }}$ & $=$ & $-0,3386+0,1372-03 N-0,6434 E-05 N^{2}$ & 0,98 \\
\hline VARI $_{\text {Green }}$ & $=$ & $0,5182+0,1437 \mathrm{E}-03 \mathrm{~N}-0,8325 \mathrm{E}-05 \mathrm{~N}^{2}$ & 0,98 \\
\hline $\operatorname{WDRVI}_{(0,05)}$ & $=$ & $-0,3615+0,3064 \mathrm{E}-02 \mathrm{~N}-0,1466 \mathrm{E}-04 \mathrm{~N}^{2}$ & 0,98 \\
\hline $\operatorname{WDRVI}_{(0,1)}$ & $=$ & $-0,0364+0,3404 \mathrm{E}-02 \mathrm{~N}-0,1627 \mathrm{E}-04 \mathrm{~N}^{2}$ & 0,97 \\
\hline \multirow[t]{2}{*}{$\operatorname{WDRVI}_{(0,2)}$} & $=$ & $0,2963+0,3014 \mathrm{E}-02 \mathrm{~N}-0,1438 \mathrm{E}-04 \mathrm{~N}^{2}$ & 0,97 \\
\hline & \multicolumn{3}{|c|}{ 3a avaliação } \\
\hline Teor de nitrogênio total & $=$ & $1,8460+0,2350 \mathrm{E}-02 \mathrm{~N}$ & 0,73 \\
\hline NDVI & $=$ & $0,8562+0,4707 \mathrm{E}-03 \mathrm{~N}-0,1084 \mathrm{E}-05 \mathrm{~N}^{2}$ & 0,96 \\
\hline VARI $_{\text {RedEdge }}$ & $=$ & $-0,3035+0,1084 \mathrm{E}-02 \mathrm{~N}-0,2365 \mathrm{E}-05 \mathrm{~N}^{2}$ & 0,96 \\
\hline VARI $_{\text {Green }}$ & $=$ & $0,5965+0,3678 \mathrm{E}-02 \mathrm{~N}-0,1015 \mathrm{E}-05 \mathrm{~N}^{2}$ & 0,96 \\
\hline $\operatorname{WDRVI}_{(0,05)}$ & $=$ & $-0,1999+0,1843 E-02 N-0,4222 E-05 N^{2}$ & 0,98 \\
\hline $\operatorname{WDRVI}_{(0,1)}$ & $=$ & $0,1383+0,1828 \mathrm{E}-02 \mathrm{~N}-0,4196 \mathrm{E}-05 \mathrm{~N}^{2}$ & 0,97 \\
\hline $\mathrm{WDRVI}_{(0,2)}$ & $=$ & $0,4471+0,1454 \mathrm{E}-02 \mathrm{~N}-0,3343 \mathrm{E}-05 \mathrm{~N}^{2}$ & 0,97 \\
\hline
\end{tabular}

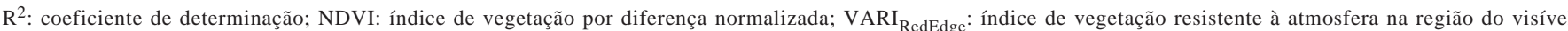

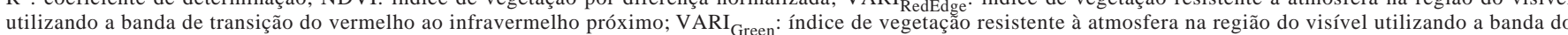
verde; WDRVI: índice de vegetação de amplo alcance dinâmico, calculado utilizando três valores de coeficientes de ponderação (0,05; 0,1 e 0,2); 1 ä avaliação: 30 dias após o 1 o corte e 20 dias após a aplicação do adubo nitrogenado; 2a avaliação: 15 dias após o 2oㅡ corte e 13 dias após a 1 a parcela do adubo nitrogenado; 3 a avaliação: 26 dias após o 2 o corte e 11 dias após a $2^{2}$ parcela do adubo nitrogenado. 
Tabela 6 - Valores máximos e mínimos ajustados dos índices de vegetação do capim-tanzânia para todas as avaliações

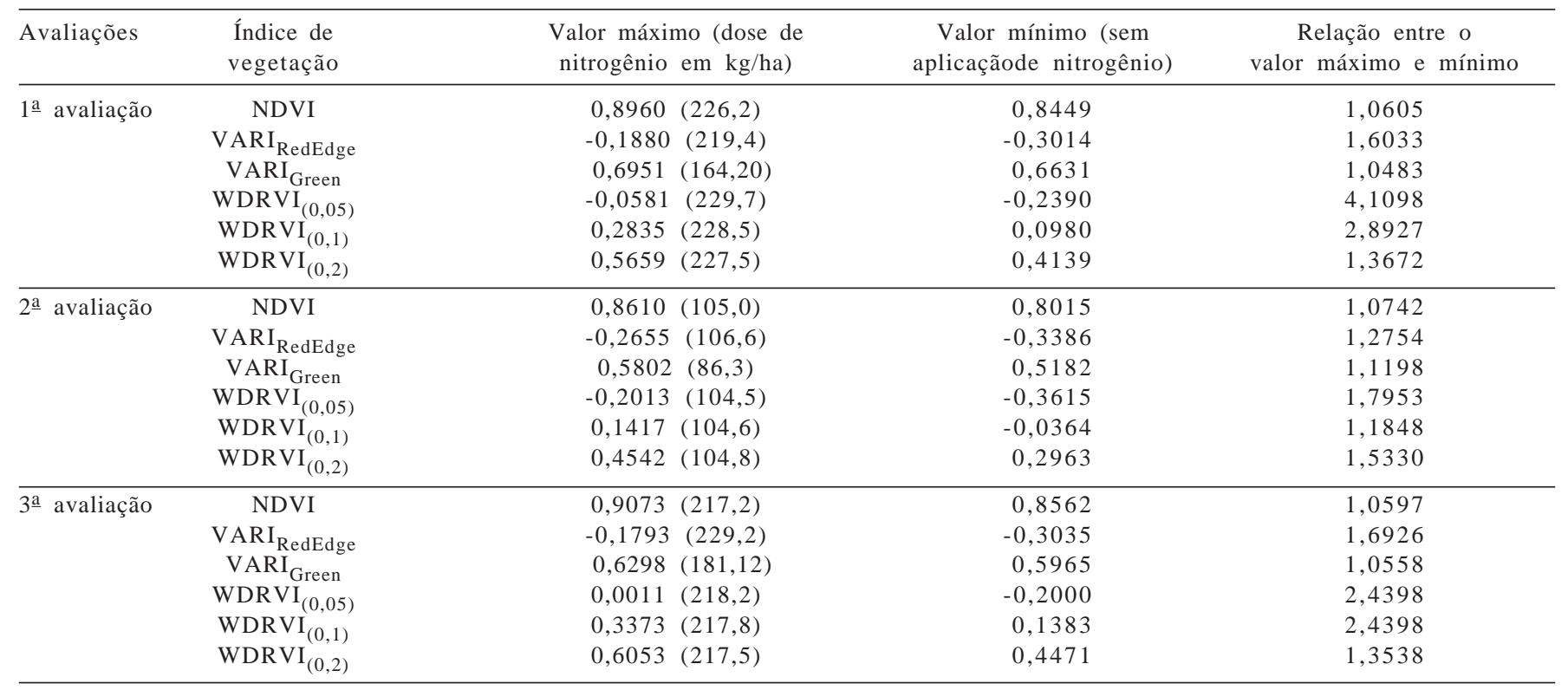

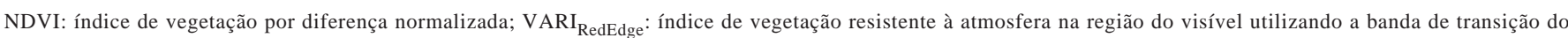
vermelho ao infravermelho próximo; VARI ${ }_{\text {Green }}$ : índice de vegetação resistente à atmosfera na região do visível utilizando a banda do verde; WDRVI: índice de vegetação de amplo alcance dinâmico, calculado utilizando três valores de coeficientes de ponderação $(0,05 ; 0,1$ e 0,2$)$. 1a avaliação: 30 dias após o 1 o corte e 20 dias após a aplicação do adubo nitrogenado; $2^{\underline{a}}$ avaliação: 15 dias após o $2^{\underline{o}}$ corte e 13 dias após a $1 \underline{a}$ parcela do adubo nitrogenado; $3^{\underline{a}}$ avaliação: 26 dias após o $2^{\underline{0}}$ corte e 11 dias após a $2^{\mathrm{a}}$ parcela do adubo nitrogenado.

Tabela 7 - Coeficientes de correlação simples entre os índices de vegetação que ajustaram o modelo e as leituras de clorofila do capimtanzânia para todas as avaliaçõe

\begin{tabular}{lccc}
\hline Índices de vegetação & 1ª avaliação & 2a avaliação & 3a avaliação \\
\hline NDVI & $0,76^{* *}$ & $0,60^{* *}$ & $0,82^{* *}$ \\
VARI $_{\text {RedEdge }}$ & $0,82^{* *}$ & $0,68^{* *}$ & $0,92^{* *}$ \\
VARI Green $_{W D V I}$ & $0,32^{\text {ns }}$ & $0,27^{\text {ns }}$ & $0,50^{* *}$ \\
$\operatorname{WDRVI}_{(0,05)}$ & $0,77^{* *}$ & $0,54^{* *}$ & $0,82^{* *}$ \\
$\operatorname{WDRVI}_{(0,2)}$ & $0,77^{* *}$ & $0,56^{* *}$ & $0,82^{* *}$ \\
\hline
\end{tabular}

${ }^{* * *}$ significativo ao nível de $1 \%$ de probabilidade. ${ }^{\mathrm{ns}}$ não-significativo ao nível de $5 \%$ de probabilidade. NDVI: índice de vegetação por diferença normalizada; VARI ${ }_{\text {RedEdge }}$ :

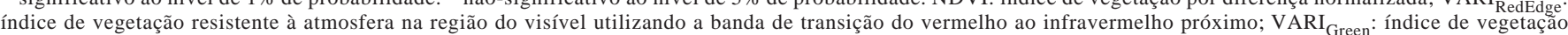
resistente à atmosfera na região do visível utilizando a banda do verde; WDRVI: índice de vegetação de amplo alcance dinâmico, calculado utilizando três valores de coeficientes de ponderação $(0,05 ; 0,1$ e 0,2$)$. 1 a avaliação: 30 dias após o 1 o corte e 20 dias após a aplicação do adubo nitrogenado; 2 a avaliação: 15 dias após o 2 o corte

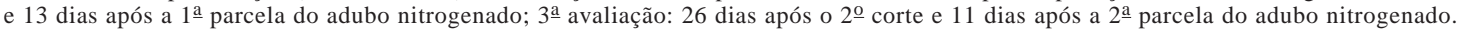

Tabela 8 - Coeficientes de correlação simples entre os cinco índices de vegetação e a massa seca do capim-tanzânia na avaliação de 20/1/2007

\begin{tabular}{lc}
\hline Índices de vegetação & Massa seca \\
\hline NDVI & $0,66^{* *}$ \\
VARI $_{\text {RedEdge }}$ & $0,69^{* *}$ \\
VARI $_{\text {Green }}$ & $0,58^{* *}$ \\
WDRVI $_{(0,05)}$ & $0,69^{* *}$ \\
WDRVI $_{(0,1)}$ & $0,68^{* *}$ \\
WDRVI$_{(0,2)}$ & $0,67^{* *}$ \\
\hline
\end{tabular}

\footnotetext{
** significativo a $1 \%$ de probabilidade. NDVI: índice de vegetação por diferença normalizada; VARI ${ }_{\text {RedEdge }}$ índice de vegetação resistente à atmosfera na região do visível utilizando a banda de transição do vermelho ao infravermelho próximo; VARI $_{\text {Green }}$ : índice de vegetação resistente à atmosfera na região do visível utilizando a banda do verde; WDRVI: índice de vegetação de amplo alcance dinâmico, calculado utilizando três valores de coeficientes de ponderação $(0,05 ; 0,1$ e 0,2$)$.
}

e concluíram que esses índices foram mais precisos e sensíveis que o NDVI para estimar o índice de área foliar e a massa seca.

Neste trabalho, pela análise de correlação simples, o índice que tendeu a apresentar o maior valor com todas as características culturais estudadas (leituras de clorofila e

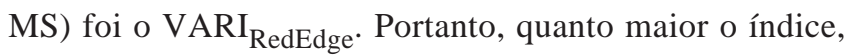
maiores os teores de MS e clorofila.

\section{Conclusões}

O índice de vegetação resistente à atmosfera na região do visível utilizando a banda de transição do vermelho ao 
infravermelho próximo e o índice de vegetação de amplo alcance dinâmico calculado utilizando os valores de coeficientes de ponderação 0,05 e 0,1 são os melhores para discriminar as doses de nitrogênio aplicadas em todos os períodos de avaliação estudados. O índice de maior correlação com as leituras de clorofila e massa seca é o índice de vegetação resistente à atmosfera na região do visível utilizando a banda de transição do vermelho ao infravermelho próximo.

\section{Literatura Citada}

BARCELlOS, A.O.; VILELA, L.; LUPINACCI, A.V. Produção animal a pasto: desafios e oportunidades. In: ENCONTRO NACIONAL DO BOI VERDE: A PECUÁRIA SUSTENTÁVEL, 3., 2001, Uberlândia. Anais... Uberlândia: Sindicato Rural de Uberlândia, 2001. p.29-64.

BULLOCK, D.G.; ANDERSON, D.S. Evaluation of the Minolta SPAD-502 chlorophyll meter for nitrogen management in corn. Journal of Plant Nutrition, n.21, p.741-755, 1998.

CANTARUTTI, R.B.; MARTINS, C.E.; CARVALHO, M.M. et al. Pastagens. In: RIBEIRO, A.C.; GUIMARÃES, P.T.G.; ALVAREZ, V.H. (Eds.) Recomendação para o uso de corretivos e fertilizantes em Minas Gerais - $5^{\text {a }}$ Aproximação. Viçosa, MG: Universidade Federal de Viçosa, 1999. p.332-341.

CARVALHO, M.M.; SARAIVA, O.F. Resposta do capim-gordura (Melinis minutiflora Beauv.) a aplicações de nitrogênio, em regime de cortes. Revista Brasileira de Zootecnia, v.16, n.5, p.442-454, 1987.

CUNHA, C.A.H. Relação entre comportamento espectral, índice de área foliar e produção de matéria seca em capim-tanzânia submetido a diferentes níveis de irrigação e doses de nitrogênio. 2004. 154f. Tese (Doutorado em Agronomia) - Escola Superior de Agricultura "Luiz de Queiroz", Piracicaba, 2004.

DIKER, K.; BAUSCH, W.C. Potencial of use of nitrogen reflectance index to estimate plant parameters and yield of maize. Biosystem Engineering, v.84, n.4, p.437-447, 2003.

DOUGHERTY, C.T.; RHYKERD, C.L. The role of nitrogen in forage-animal production. In: HEATH, M.E.; BARNES, R.F.; METCALFE, D.S. (Eds.) Forages: the science of grassland agriculture. 5.ed. Iowa: State University, 1985. p.318-325.

GITELSON, A.A.; KAUFMAN, Y.J.; STARK, R. et al. Novel algorithms for remote estimation of vegetation fraction. Remote Sensing of Environment, v.80, p.76-87, 2002.

GITELSON, A.A.; VIÑA, A.; ARKEBAUER, T.J. et al. Remote estimation of leaf area index and green leaf biomass in maize canopies. Geophysical Research Letters, v.30, n.5, p.52 (1-4), 2003.
GITELSON, A.A. Wide dynamic range vegetation index for remote quantification of biophysical characteristics of vegetation. Journal Plant Physiology, v.161, p.165-173, 2004.

GOMES, F.P. Curso de estatística experimental. 9.ed. Piracicaba: Escola Superior de Agricultura "Luiz de Queiroz", 1981. 430p.

MOREIRA, L.M.; DA FONSECA, D.M.; VÍTOR, C.M.T. et al. Renovação de pastagem degradada de capim-gordura com a introdução de forrageiras tropicais adubadas com nitrogênio ou em consórcios. Revista Brasileira de Zootecnia, v.34, n.2, p.442-453, 2005.

MOREIRA, M.A. Fundamentos do sensoriamento remoto e metodologias de aplicação. 3.ed. Viçosa, MG: Universidade Federal de Viçosa, 2005. 320p.

OLIVEIRA, O.C.; OLIVEIRA, I.P.; FERREIRA, E. et al. Response of degraded pastures in the Brazilian Cerrado to chemical fertilization. Pastures Tropicales, v.13, n.1, p.14-18, 2001.

PONZONI, F.J. Comportamento espectral da vegetação. In: MENESES, P.R.; MADEIRA NETTO, J.S. (Eds.) Sensoriamento remoto: refletância dos alvos naturais. Brasília: UnB; Planaltina: Embrapa Cerrados, 2001. p.157-195.

PRIMAVESI, A.C.; PRIMAVESI, O.; CORRÊA, L.A. et al. Nitrogen fertilization in coastcross grass: effects on nutrient extraction and apparent nitrogen recovery. Revista Brasileira de Zootecnia, v.33, n.1, p.68-78, 2004.

QUEIROZ, D.M.; DIAS, G.P.; MANTOVANI, E.C. Agricultura de Precisão na Produção de Grãos. In: BORÉM, A.; GIUDICE, M.P.; QUEIROZ, D.M. et al. (Eds.) Agricultura de precisão. Viçosa, MG: Universidade Federal de Viçosa, 2000. p.1-41.

ROUSE, J.W.; HAAS, R.H.; SCHELL, J.A. et al. Monitoring vegetation systems in the Great Plains with ERTS. In: ERTS-1 SYMPOSIUM, 3., 1973, Washington. Proceedings... Washington: NASA, 1974. v.1, p.309-317.

SILVA JR., M.C. Deteç̧ão do efeito da adubação nitrogenada em brachiaria decumbens utilizando técnicas de sensoriamento remoto. 2006. 96f. Dissertação (Mestrado em Engenharia Agrícola) - Universidade Federal de Viçosa, Viçosa, MG, 2006.

STATISTICAL ANALYSIS SYSTEM - SAS. SASOnline Doc. Version 8. Cary: SAS Institute, 1999. (CD-ROM).

VIÑA, A.; GITELSON, A.A.; RUNDQUIST, D.C. et al. Monitoring maize (Zea mays L.) phenology with remote sensing. Agronomy Journal, v.96, p.1139-1147, 2004.

UNITED STATES DEPARTMENT OF AGRICULTURE - USDA. [2009]. Livestock and Poultry: world markets and trade. Disponível em: <http://www.usda.gov/wps/portal/usdahome>. Acesso em: 16/7/2009.

YODER, B.J.; PETTIGREW-CROSBY, R.E. Predicting nitrogen and chlorophyll content and concentrations from reflectance spectral $(400-2500 \mathrm{~nm})$ at leaf and canopy scales. Remote Sensing of Environment, v.53, n.3, p.199-211, 1995.

ZOTARELLI, L.; CARDOSO, E.G.; PICCININ, J.L. et al. Calibração do medidor de clorofila Minolta SPAD-502 para uso na cultura do milho. Seropédica: Embrapa Agrobiologia, 2002. 4p. (Comunicado Técnico, 55). 